\title{
Higher dietary diversity is related to better visual and auditory sustained attention
}

\author{
Farideh Shiraseb ${ }^{1}$, Fereydoun Siassi ${ }^{1 *}$, Mostafa Qorbani ${ }^{2}$, Gity Sotoudeh ${ }^{1 *}$, Reza Rostami ${ }^{3}$, \\ Elham Narmaki ${ }^{1}$, Parvaneh Yavari ${ }^{1}$, Mohadeseh Aghasi ${ }^{1}$ and Osman Mohammed Shaibu ${ }^{1}$ \\ ${ }^{1}$ Department of Community Nutrition, School of Nutritional Sciences and Dietetics, Tehran University of Medical Sciences, \\ Hojatdost Street, Naderi Street, Keshavarz Blv., Tehran, Iran \\ ${ }^{2}$ Department of Community Medicine, School of Public Health, Alborz University of Medical Sciences, Edari, Taleghani Blv., \\ Taleghani Square, Karaj, Iran \\ ${ }^{3}$ Department of Psychology, Tehran University, Chamran Street, Tebran, Iran
}

(Submitted 13 August 2015 - Final revision received 7 January 2016 - Accepted 22 January 2016 - First published online 23 February 2016)

\section{Abstract}

Attention is a complex cognitive function that is necessary for learning, for following social norms of behaviour and for effective performance of responsibilities and duties. It is especially important in sensitive occupations requiring sustained attention. Improvement of dietary diversity (DD) is recognised as an important factor in health promotion, but its association with sustained attention is unknown. The aim of this study was to determine the association between auditory and visual sustained attention and DD. A cross-sectional study was carried out on 400 women aged 20-50 years who attended sports clubs at Tehran Municipality. Sustained attention was evaluated on the basis of the Integrated Visual and Auditory Continuous Performance Test using Integrated Visual and Auditory software. A single 24-h dietary recall questionnaire was used for DD assessment. Dietary diversity scores (DDS) were determined using the FAO guidelines. The mean visual and auditory sustained attention scores were 40.2 (SD 35.2) and 42.5 (SD 38), respectively. The mean DDS was 4.7 (SD 1.5). After adjusting for age, education years, physical activity, energy intake and BMI, mean visual and auditory sustained attention showed a significant increase as the quartiles of DDS increased $(P=0.001)$. In addition, the mean subscales of attention, including auditory consistency and vigilance, visual persistence, visual and auditory focus, speed, comprehension and full attention, increased significantly with increasing DDS $(P<0 \cdot 05)$. In conclusion, higher DDS is associated with better visual and auditory sustained attention.

\section{Key words: Visual and auditory sustained attention: Dietary diversity: Women: Sustained attention}

Cognitive performance has several domains - namely, attention, executive function, memory, language and emotion ${ }^{(1)}$. Attention is a cognitive process that is defined as the selective focus on one aspect of the environment, neglecting other aspects ${ }^{(2)}$. There are five types of attention: (1) focused attention or the ability to respond individually to visual, auditory or sensory stimulus; (2) sustained attention or the ability to sustain a steady-state response; (3) selective attention or the ability to maintain a fixed set of responses in the face of distraction; (4) alternating attention or the ability of mental flexibility to shift attention and make a decision between different tasks; and (5) divided attention or the ability to respond to several tasks at the same time $e^{(3,4)}$.

Among these types of attention, sustained attention seems very important. Some sensitive professions or occupations, including driving, pilotage, nursing and medical profession, require sustained attention. When a repetitive stimulus is presented for a long period of time, it becomes difficult for people to maintain their attention ${ }^{(4,5)}$. Attention maintenance for a long time makes a person feel sleepy and lowers the level of consciousness as a result of decreased vigilance and reactive inhibition $^{(6,7)}$.

Different proportions of macronutrients and the amounts of some micronutrients may have an effect on cognitive performance and effective attention ${ }^{(5,6)}$. Most nutrients affect the structure of the brain and neurogenesis and therefore may affect cognition performance ${ }^{(6)}$. Vitamins, minerals, essential amino acids and essential fatty acids, including $n-3$ PUFA, have been identified to be involved in cerebral functioning ${ }^{(6,7)}$. More so, caffeine supplementation might be effective in improving attention and in increasing alertness ${ }^{(8,9)}$.

Consumption of different food groups has been reported to be associated with general cognition ${ }^{(10)}$. The consumption of fruits and vegetables has been demonstrated to have beneficial effects on general cognitive functioning ${ }^{(11)}$. Other studies have confirmed this accession with the indication that a higher vegetable intake is associated with less decline in general

Abbreviations: CPT, Continuous Performance Test; DD, dietary diversity; DDS, dietary diversity scores; IVA, Integrated; Visual and Auditory; MET, metabolic equivalent task

*Corresponding authors: F. Siassi, fax +98 218897 4462, siassif@tums.ac.ir; G. Sotoudeh, fax +98 218897 4462, email gsotodeh@tums.ac.ir 
cognition and memory ${ }^{(12,13)}$. Fruits and vegetables are known to contain a variety of substances, such as vitamins, antioxidants, minerals and phytochemicals, and have been reported to be beneficial in cognitive functioning ${ }^{(14)}$.

Nutritional adequacy is assessed using nutrient intake adequacy, dietary diversity (DD) and balanced diet ${ }^{(15)}$. Balanced nutritional status is crucial for proper brain growth, development and normal cognitive function ${ }^{(16)}$. DD has been recognised as a proxy measure and practical indicator of diet quality ${ }^{(17-19)}$. In developing countries, grains are the most common staple food, and diet has low diversity, which can lead to micronutrient deficiency ${ }^{(20)}$. Therefore, health promotion strategies could include the encouragement of improved DD.

A diversified diet may have several effects, which include the lower intake of unhealthy food and additives. Moreover, different nutrients exist in various foods, and a low DD might reduce access to some nutrients. Improving DD is among the key solutions for preventing the prevalence of hidden hunger ${ }^{(21)}$. DD ensures a healthy diet that contains a balanced and adequate combination of macronutrients and micronutrients ${ }^{(19)}$. In addition, DD may prevent chronic diseases like hypertension, CVD, cancer and type 2 diabetes, and might increase the longevity and quality of life $e^{(22,23)}$. Dietary diversity score (DDS) is usually used for the determination of DD and is calculated on the basis of the number of different food groups consumed over a given period of time ${ }^{(24)}$. The results of some studies have revealed that DDS $<2$ is associated with increased mortality rate of $40 \%$ for men and $50 \%$ for women ${ }^{(19)}$. Greater DD is reported to be associated with decreased morbidity and mortality rate and may also increase academic performance and quality of life ${ }^{(25)}$. Therefore, it seems that, with good macro and micronutrient balance, DD may affect cognitive performance in the area of attention. There have been no such studies on the relationship between cognitive performance and DDS. Thus, the aim of this study was to investigate the association between DDS and visual and auditory sustained attention.

\section{Methods}

\section{Population}

The subjects were recruited from municipal sports clubs in Tehran from May 2013 to February 2014. A large number of women at these clubs are usually willing to participate in research. The aim of the study was to assess DD and its association with sustained attention, anthropometric measurements, body composition and blood antioxidant levels in healthy women. The detailed methods of the study were described previously ${ }^{(26,27)}$ and are briefly described here. The participants were 400 healthy women within the reproductive age of 20-50 years who attended municipal sports clubs in the west, northwest and southwest of Tehran. As physical activity is accompanied by higher blood antioxidant levels ${ }^{(28)}$ and better cognitive performance ${ }^{(29)}$, subjects who were participating in physical exercise for the first time or had participated in it a week before the beginning of the study were selected.

The inclusion and exclusion criteria were determined before the beginning of the study. Women diagnosed with any mental or physical disease, including Fe-deficiency anaemia, pregnant and lactating women and women who were on medication or had been taking mineral and/or vitamins for at least a month or reported consuming tobacco products were excluded. Professional athletes were also excluded from the study. As the sample size was not very large, the study was restricted to only women.

Seven municipal districts are located in the northwest, southwest and west of Tehran. The list of all sports clubs in these districts was provided by the Sports Organization. A systematic random sampling technique was used to select two sports clubs from each district, and collectively fourteen clubs were selected from the seven districts. Using systematic random sampling, approximately thirty women were selected from each sports club. After presenting oral and written explanation on the objectives and methodology of the study, informed consent was obtained from the participants. The study protocol was approved by the Medical Ethics Committee of Tehran University of Medical Sciences.

\section{Dietary intake assessment}

A single 24-h dietary recall questionnaire was undertaken by a trained nutritionist using face-to-face interviews. A single 24-h recall is recommended for assessing $\operatorname{DDS}^{(24,30)}$. A detailed description of the consumed foods on the previous day and night was collected using common household utensils to estimate the proportion of intake. Content of mixed foods was analysed on the basis of their ingredients, and nutrient intake was calculated using food composition guidelines ${ }^{(31)}$. Dietary analyses were performed using a Nutritionist version 4 .

\section{Dietary diversity score}

DDS was assessed using the FAO guidelines for measuring individual DD, which is not population, culture or location specific $^{(24)}$. Appropriate translation into Farsi language and adaptation of the food lists to the available foods were performed before data collection. The food items were assigned to nine food groups on the basis of the FAO guidelines: 1. starchy staples and white roots; 2. vitamin A-rich fruits and vegetables; 3 . dark green leafy vegetables; 4 . other fruits and vegetables; 5 . organ meat; 6. meat and fish; 7. eggs; 8. legumes, nuts and seeds; and 9. milk and milk products. DDS was calculated considering consumption of at least half of a serving of any food item from each of the mentioned food groups. The maximum score was 9, with 1 point assigned to each food group consumed ${ }^{(24)}$.

\section{Physical activity and anthropometric assessment}

Physical activity was assessed through interview with the help of a questionnaire that classified physical activity according to the metabolic equivalent task (MET). The questionnaire is a simple tool divided into nine rows according to the intensity of exercise (MET), with MET value ranging from light- to high-intensity activities: $0 \cdot 9,1,1.5,2,3,4,5,6$ and >6. MET/h for each activity was calculated by multiplying the hours spent 
on each activity by the assigned MET score. The questionnaire has been used in European studies and compared with the accelerometer for its validity (model 7164; CSA Inc.) ${ }^{(32)}$. The validity and reliability of the questionnaire was confirmed by Kelishadi et $a l .{ }^{(33)}$ with a positive correlation with the International Physical Activity Questionnaire and a 7-d physical activity record.

All participants were weighted while wearing light clothes and no shoes, and the reading was taken at the nearest $0.1 \mathrm{~kg}$ using an electronic scale (Seca). Height was measured without shoes and the reading was taken at the nearest $0 \cdot 1 \mathrm{~cm}$ using a Seca wall-mounted stadiometer. BMI was calculated as body weight divided by the square of height in metres $\left(\mathrm{kg} / \mathrm{m}^{2}\right)$.

\section{Visual and auditory sustained attention assessment}

Sustained attention was assessed using the Integrated Visual and Auditory Continuous Performance Test (IVA CPT), which is reported to be one of the most valid tests for visual and auditory attention and response control for individuals aged 6-96 years ${ }^{(34)}$. The IVA CPT was developed by Sandford \& Turner ${ }^{(34)}$. The scales of the IVA CPT are described in Fig. 1. IVA is a computerised test that consists of an ongoing series of stimuli, and the operator of the equipment should check for the presence of predetermined targets. Stimuli may be presented auditorily or visually. This test has four stages: (1) visual warm-up for $1 \mathrm{~min}$ and auditory warm-up for $1 \mathrm{~min}$, (2) exercise for 1-1.5 min, (3) main CPT for $13 \mathrm{~min}$; and (4) cool down. The IVA PLUS software version 2008.1 was used in this study (Brain Train Company) and a laptop (Core i5; Acer) connected to an auxiliary 'mouse' and earphones (Griffin) was used for test administration.

The computer keyboard was used for moving from one stage to the next. Together with the initial explanations on how to do the test, the test took $20 \mathrm{~min}$ for each participant. The participants were requested to focus on the computer monitor for $20 \mathrm{~min}$ and to click the mouse when presented with a visual or auditory ' 1 ' and not to click when presented with a ' 2 '. Both speed and precision are important in this test and the reactions were evaluated in milliseconds. The test results are composed of two main scores in attention and response control performance domains. The test provides four separate scores, which include full scale response control, full scale attention, attribute and symptomatic quotient in auditory and visual domains, with twelve scores for subscale quotients ${ }^{(34)}$.

The response control quotient is a measure of impulsivity and committing errors, which includes prudence, consistency and stamina subscales. Prudence measures impulsivity and response inhibition as evidenced by three types of errors of commission. The auditory consistency subscale is an indicator of sustained response, reliability and validity of the auditory reaction time. Stamina identifies problems related to sustaining attention over time.

Full scale attention quotient measures attention and omission errors and includes vigilance, focus and speed subscales. The auditory vigilance subscale as an indicator of attention function detects two different types of errors of omission. Focus and speed are indicators of the degree of variability in processing speed and the average reaction time for correct responses, respectively.

The attribute quotient is a measure of individual learning styles, which includes balance and readiness subscales. Balance shows whether participants process information more quickly visually or aurally. Readiness measures preparedness to keep up with tasks faster whenever the demand is higher and vice versa.

The symptomatic quotient has three subscales that include comprehension, persistence and sensory/motor. The comprehension subscale indicates random responding by measuring idiopathic errors. The persistence subscale identifies the degree of fatigue and is based on the motivation or ability to stay on task for a specific period of time. Sensory/motor measures reaction

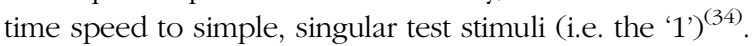

All scores were reported separately for the test-taker's auditory and visual modalities and then as a combined score. Quotient scores were used instead of raw scores for all scales and subscales, whereby higher scores reflect better levels of performance.

Participants were contacted a day before the test and were provided with the methodology and requirements of the test, including refraining from taking drugs that could affect alertness. They were encouraged to have enough sleep and avoid stress, which includes family quarrels, a night before the test, have a snack before the test, and abstain from caffeinecontaining drinks and foods during the intake of snack and before the test. The participants who did not fulfil these requirements or had pain in any part of the body were excluded from the study ( $n$ 11).

\section{Statistical analysis}

Statistical analyses were performed using SPSS version 16 (SPSS Inc.). DDS was determined by categorising DDS into quartiles (Q) as follows: DDS score ranging from 2 to 3 categorised as Q1, 4 as Q2, 5 as Q3 and 6-9 as Q4. Correlation of attention scales and subscales with energy intake, physical activity, BMI and years of education was assessed by means of Pearson's correlation coefficient. ANOVA was used to compare the crude means of scales and subscales of auditory and visual sustained attention across the quartiles of DDS. ANCOVA was used to compare the means of these variables after adjustment for age, years of education, physical activity, total energy intake and BMI across the quartiles of DDS. A value of $P<0.05$ was considered statistically significant.

\section{Results}

Table 1 shows the general demographic characteristics, DDS status, anthropometric measurement and visual and auditory sustained attention of the participants. The mean values of some nutrients' intake by the quartiles of DDS are shown in Fig. 2-4. The mean daily intake of energy from carbohydrate (\%), Se, dietary fibre, Fe, $\mathrm{Zn}$ and pyridoxine increased with increase in the quartiles of DDS.

Correlation of attention scales and subscales in visual and auditory domain with energy intake, physical activity 

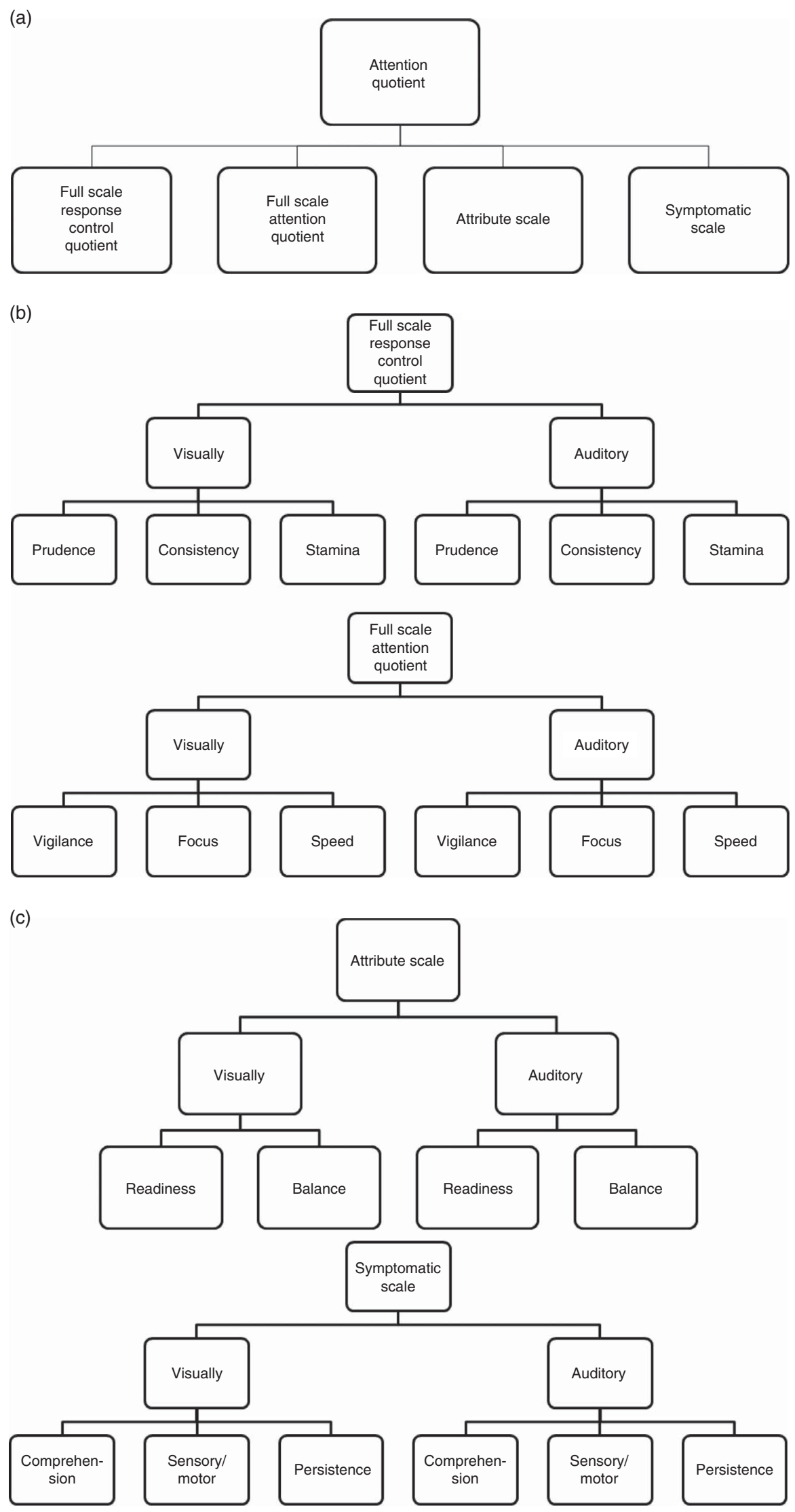

Fig. 1. The scales of the Integrated Visual and Auditory Continuous Performance Test. (a) Categories of integrated visual and auditory continuous performance test. (b) Visually and auditory subscales of full scale response control quotient and full scale attention quotient. (c) Visually and auditory subscales of attribute and symptomatic scales. 
Table 1. General characteristics, dietary diversity status, anthropometric measurement and visual and auditory sustained attention of participants

(Mean values, ranges and standard deviations)

\begin{tabular}{|c|c|c|c|}
\hline Variables & Mean & Range & SD \\
\hline Age (years) & & & 7.9 \\
\hline Years of education & & & 3.1 \\
\hline Physical activity score (MET-h/d) & & & 5.5 \\
\hline Weight $(\mathrm{kg})$ & & & $12 \cdot 8$ \\
\hline Height (cm) & & & 8.9 \\
\hline BMI $\left(\mathrm{kg} / \mathrm{m}^{2}\right)$ & & & 4.8 \\
\hline Energy intake (kJ) & & & $3152 \cdot 2$ \\
\hline Energy intake (kcal) & & & 753.4 \\
\hline Dietary diversity score & & & 1.5 \\
\hline \multicolumn{4}{|l|}{ Full response control } \\
\hline Visual & 111.6 & $0-140$ & 26.8 \\
\hline Auditory & $101 \cdot 1$ & $49-136$ & $17 \cdot 7$ \\
\hline \multicolumn{4}{|l|}{ Prudence } \\
\hline Visual & 92.9 & $0-117$ & $23 \cdot 3$ \\
\hline Auditory & 93.0 & $0-116$ & 21.0 \\
\hline \multicolumn{4}{|l|}{ Consistency } \\
\hline Visual & $121 \cdot 0$ & $0-153$ & $25 \cdot 7$ \\
\hline Auditory & $108 \cdot 2$ & $63-142$ & $15 \cdot 6$ \\
\hline \multicolumn{4}{|l|}{ Stamina } \\
\hline Visual & 103.5 & $0-136$ & $19 \cdot 4$ \\
\hline Auditory & 98.8 & $65-145$ & $15 \cdot 4$ \\
\hline \multicolumn{4}{|l|}{ Full attention } \\
\hline Visual & 53.6 & $0-121$ & 30.7 \\
\hline Auditory & 51.9 & $0-116$ & $29 \cdot 3$ \\
\hline \multicolumn{4}{|l|}{ Vigilance } \\
\hline Visual & $59 \cdot 4$ & $0-100$ & $32 \cdot 1$ \\
\hline Auditory & 60.9 & $0-128$ & $41 \cdot 1$ \\
\hline \multicolumn{4}{|l|}{ Focus } \\
\hline Visual & $119 \cdot 1$ & $0-151$ & $23 \cdot 1$ \\
\hline Auditory & $113 \cdot 0$ & $22-160$ & $13 \cdot 4$ \\
\hline \multicolumn{4}{|l|}{ Speed } \\
\hline Visual & 24.0 & $0-115$ & $14 \cdot 1$ \\
\hline Auditory & $24 \cdot 6$ & $0-114$ & $15 \cdot 1$ \\
\hline \multicolumn{4}{|l|}{ Attribute scale } \\
\hline \multicolumn{4}{|l|}{ Readiness } \\
\hline Visual & $100 \cdot 5$ & $0-138$ & $23 \cdot 3$ \\
\hline Auditory & $107 \cdot 0$ & $0-160$ & $18 \cdot 1$ \\
\hline Balance & $116 \cdot 9$ & $0-159$ & 16.5 \\
\hline \multicolumn{4}{|l|}{ Symptomatic scale } \\
\hline \multicolumn{4}{|l|}{ Comprehension } \\
\hline Visual & $66 \cdot 0$ & $0-107$ & 42.5 \\
\hline Auditory & $63 \cdot 7$ & $0-111$ & $44 \cdot 1$ \\
\hline \multicolumn{4}{|l|}{ Persistence } \\
\hline Visual & $92 \cdot 6$ & $0-160$ & 31.8 \\
\hline Auditory & 99.8 & $0-88$ & $21 \cdot 2$ \\
\hline \multicolumn{4}{|l|}{ Sensory/motor } \\
\hline Visual & 30.4 & $0-87$ & 24.9 \\
\hline Auditory & $92 \cdot 6$ & $0-88$ & 31.8 \\
\hline \multicolumn{4}{|l|}{ Sustained attention } \\
\hline Visual & $40 \cdot 2$ & $0-99$ & $35 \cdot 2$ \\
\hline Auditory & 42.5 & $0-108$ & 38.0 \\
\hline
\end{tabular}

MET, metabolic equivalent task.

score, BMI and years of education is shown in Table 2. Visual and auditory prudence, full attention, focus, sensory/motor, sustained attention, visual full response control, consistency, speed, comprehension and auditory vigilance were directly correlated to years of education $(P<0 \cdot 01)$. In addition, visual focus was directly related to physical activity $(P<0 \cdot 05)$. Auditory stamina and readiness were directly correlated to energy intake, and visual focus and persistence were inversely correlated to energy intake $(P<0 \cdot 05)$.
Table 3 shows crude and adjusted mean of visual and auditory sustained attention by the quartiles of DDS. The mean visual and auditory sustained attention increased significantly with increase in the quartiles of DDS (model 1) and remained significant after adjusting for age, years of education and physical activity (model 2), and for energy intake and BMI in addition to the above-mentioned variables (model 3) $(P<0.001)$. Moreover, in models 2 and 3, as the quartiles of DDS increased, there was a corresponding increase in the mean subscales of attention, including auditory consistency and 


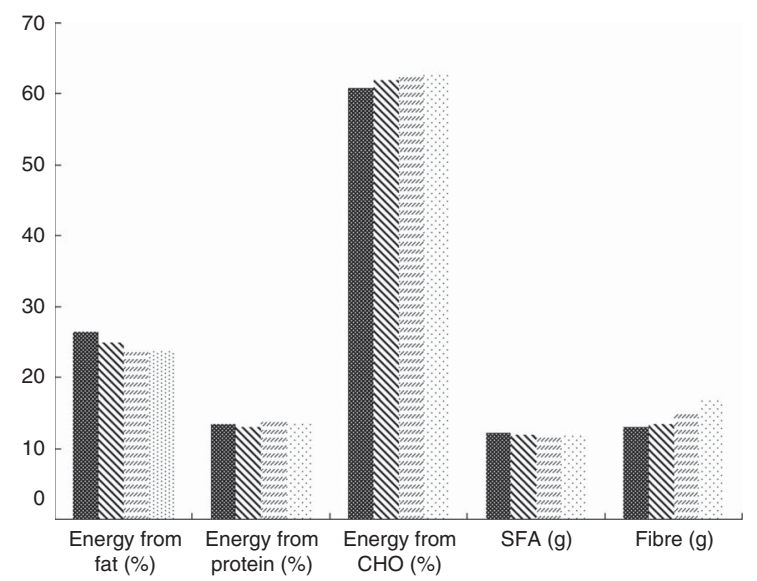

Fig. 2. Mean of macronutrients, SFA and dietary fibre intake by dietary

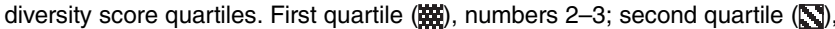
number 4 ; third quartile ( $\mathrm{B}$ ), number 5 ; fourth quartile (B) numbers $6-9$; $\mathrm{CHO}$, carbohydrate.

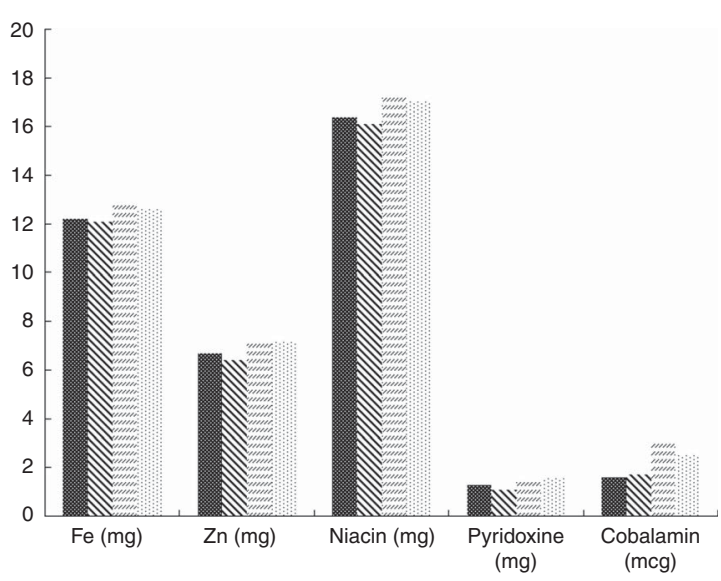

Fig. 3. Mean iron, zinc, niacin, pyridoxine and cobalamin intake by dietary diversity score quartiles. First quartile ( number 4 ; third quartile $(\mathrm{B})$, number 5 ; fourth quartile ( numbers $6-9$.

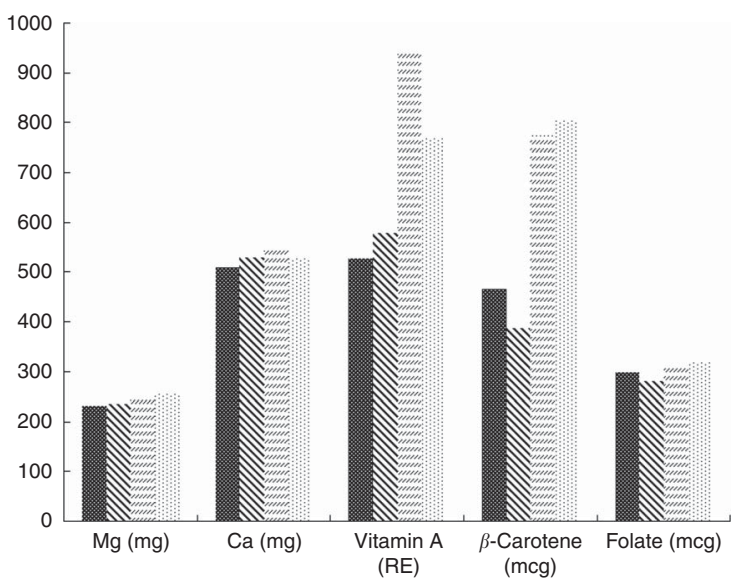

Fig. 4. Mean magnesium, calcium, vitamin $\mathrm{A}, \beta$-carotene and folate intake by dietary diversity score quartiles. First quartile (䉂), numbers $2-3$; second quartile $(\mathbf{\$})$, number 4 ; third quartile (国), number 5 ; fourth quartile ( numbers 6-9; RE, retinol equivalent. vigilance, visual persistence, visual and auditory focus, speed, comprehension and full attention $(P<0 \cdot 05)$.

\section{Discussion}

This is the first time that the association between DDS and sustained attention is being investigated. The present study found a significant positive association between sustained attention in both visual and auditory domains and DDS. In addition, some subscales of sustained attention including auditory consistency and vigilance, visual and auditory focus, speed, comprehension, full attention and visual persistence were found to be directly related to DDS.

A study among older adults found higher variety in fruit and vegetable consumption to be associated with improved memory, executive function and attention ${ }^{(35)}$. Fruits and vegetables have been found to have positive effects on the function of the brain and vessels and to prevent the general cognitive decline ${ }^{(13)}$. Intake of these food groups in the elderly is reported to be associated with improved memory, fluency and general cognitive function ${ }^{(12)}$. A 13-year follow-up study of French adults revealed that fruit and vegetable intake and fruit intake alone were associated with verbal memory improvement. However, fruit and vegetable intake and vegetable intake alone were found to be associated with a decline in executive function ${ }^{(35)}$.

A systematic review of cohort studies has shown that a higher intake of vegetables is associated with a lower risk for dementia and a slower rate of cognitive decline. However, higher fruit consumption is not related to lower risk for dementia ${ }^{(36)}$.

Dietary pattern based on complex carbohydrates, fibres, cereals, red wine, fresh fruit and vegetables, and vegetable fat appears to protect against cognitive decline. Furthermore, a clear reduction of age-related cognitive decline risk has been found in a population sample with high intake of olive oil, which might be due to the presence of high MUFA or antioxidants ${ }^{(37)}$.

Morbidity of neurodegenerative diseases has been attributed to oxidative stress caused by many factors including inappropriate nutrition. Oxidative stress might play a pivotal role in the progression of neurodegenerative diseases ${ }^{(38)}$. Fruits, vegetables and grains are rich sources of antioxidant compounds and phytochemicals, including vitamin E, vitamin C, Se, lycopene and resveratrol, which might have neuroprotective effects ${ }^{(39)}$.

It has been reported that subjects with a high daily intake of fruits and vegetables have higher blood antioxidant levels and better cognitive performance ${ }^{(11)}$. In the participants of this study, improved visual and auditory sustained attention was previously reported to be associated with higher blood antioxidant status ${ }^{(26)}$.

DD has been recognised as a key element of high-quality $\operatorname{diets}^{(40)}$. The result of previous studies has shown higher DDS to be associated with greater intake of all nutrients in adults $^{(41,42)}$. In addition, the action of many nutrients is affected by the presence of other nutrients and the balance of dietary intake ${ }^{(43)}$. Therefore, higher DD, which provides higher nutrients and non-nutrients and their balance, might be related to improved sustained attention.

In the present study, when the subscale scores were examined in relation to DDS, it was found that better mental 
Table 2. Pearson's correlation coefficient of attention scales and subscales in visually and auditory domain with energy intake, physical activity score, $\mathrm{BMI}$ and years of education

\begin{tabular}{|c|c|c|c|c|c|c|}
\hline $\begin{array}{l}\text { Scales and subscales } \\
\text { of attention }\end{array}$ & Domain & $\begin{array}{l}\text { Energy intake } \\
\text { (kcal) }\end{array}$ & $\begin{array}{l}\text { Energy intake } \\
(\mathrm{kJ})\end{array}$ & $\begin{array}{l}\text { Physical activity score } \\
\text { (MET-h/d) }\end{array}$ & BMI $\left(\mathrm{kg} / \mathrm{m}^{2}\right)$ & Years of education \\
\hline \multirow[t]{2}{*}{ Full response control } & Visual & 0.03 & 0.16 & 0.05 & -0.07 & $0.1^{\star *}$ \\
\hline & Auditory & 0.05 & 0.21 & 0.02 & -0.07 & 0.08 \\
\hline \multirow[t]{2}{*}{ Prudence } & Visual & -0.01 & -0.04 & 0.03 & $-0.1^{*}$ & $0.1^{\star *}$ \\
\hline & Auditory & 0.01 & 0.04 & 0.03 & $-0 \cdot 1^{*}$ & $0 \cdot 1^{\star \star}$ \\
\hline \multirow[t]{2}{*}{ Consistency } & Visual & -0.02 & -0.08 & 0.02 & -0.04 & $0 \cdot 1^{\star *}$ \\
\hline & Auditory & 0.01 & 0.04 & 0.03 & 0.05 & -0.01 \\
\hline \multirow[t]{2}{*}{ Stamina } & Visual & 0.02 & 0.08 & 0.01 & -0.03 & 0.08 \\
\hline & Auditory & $0.1^{\star \star}$ & $0.4^{\star \star}$ & -0.01 & -0.03 & -0.04 \\
\hline \multirow[t]{2}{*}{ Full attention } & Visual & -0.003 & -0.013 & -0.006 & -0.05 & $0.1^{\star \star}$ \\
\hline & Auditory & -0.01 & -0.04 & 0.02 & -0.06 & $0 \cdot 1^{* *}$ \\
\hline \multirow[t]{2}{*}{ Vigilance } & Visual & -0.03 & -0.16 & 0.02 & 0.007 & 0.05 \\
\hline & Auditory & 0.01 & 0.04 & 0.05 & -0.05 & $0.1^{\star *}$ \\
\hline \multirow[t]{2}{*}{ Focus } & Visual & $-0.1^{\star}$ & $-0.4^{*}$ & $0.1^{*}$ & -0.09 & $0.1^{* *}$ \\
\hline & Auditory & 0.03 & 0.16 & 0.01 & 0.06 & $0 \cdot 1^{\star *}$ \\
\hline \multirow[t]{2}{*}{ Speed } & Visual & 0.07 & 0.29 & -0.07 & -0.08 & $0 \cdot 2^{* *}$ \\
\hline & Auditory & -0.09 & -0.38 & -0.04 & -0.09 & 0.1 \\
\hline \multicolumn{7}{|l|}{ Attribute scale } \\
\hline \multirow[t]{2}{*}{ Readiness } & Visual & 0.03 & 0.12 & 0.006 & 0.01 & 0.05 \\
\hline & Auditory & $0.1^{*}$ & $0.4^{*}$ & -0.03 & -0.03 & 0.09 \\
\hline Balance & - & -0.7 & $-2 \cdot 9$ & -0.04 & $0.1^{\star *}$ & -0.04 \\
\hline \multicolumn{7}{|l|}{ Symptomatic scale } \\
\hline \multirow[t]{2}{*}{ Comprehension } & Visual & -0.004 & -0.016 & 0.01 & 0.02 & $0 \cdot 1^{* *}$ \\
\hline & Auditory & -0.01 & -0.04 & 0.03 & -0.002 & 0.09 \\
\hline \multirow[t]{2}{*}{ Persistence } & Visual & $-0 \cdot 1^{\star}$ & $-0.4^{\star}$ & 0.05 & -0.07 & -0.02 \\
\hline & Auditory & 0.05 & 0.20 & -0.08 & -0.05 & 0.09 \\
\hline \multirow[t]{2}{*}{ Sensory/motor } & Visual & 0.02 & 0.08 & -0.03 & $-0 \cdot 1^{\star \star}$ & $0 \cdot 1^{\star \star}$ \\
\hline & Auditory & 0.01 & 0.04 & -0.02 & -0.04 & $0 \cdot 2^{* \star}$ \\
\hline \multirow[t]{2}{*}{ Sustained attention } & Visual & 0.02 & 0.08 & -0.01 & -0.02 & $0 \cdot 2^{\star *}$ \\
\hline & Auditory & 0.01 & 0.04 & 0.02 & -0.08 & $0 \cdot 1^{\star *}$ \\
\hline
\end{tabular}

MET, metabolic equivalent task

${ }^{\star} P<0.05,{ }^{*} P<0.01$

processing speed and reduction in mean reaction time for correct responses were related to higher DDS. With increasing quartiles of DDS, there was a corresponding increase in the mean value of consistency and vigilance, which indicates improvement in sustained response and reduction in errors of omission. With increasing quartiles of DDS, there was a corresponding increase in the mean value of focus and speed, which indicates attention sustenance and maintenance, and better processing speed.

It seems that an increase in DDS might be related to lower idiopathic errors in both visual and auditory domains. When examined in relation to DDS, the present study findings indicate that better or higher DDS is related to lower fatigue in visual and auditory domains and is also related to improved steadiness of responses as higher DDS was found to be inversely associated with fatigue in visual and auditory domains.

The full attention as an indication of impulsivity and attention deficiency $^{(34)}$ showed a significant positive association with DDS before and after adjusting for confounders, which shows that the better attention and response are related to higher DDS.

With increasing quartiles of the DDS, there was a corresponding increase in the mean value of some subscales of response control and attribute scales. However, these scales have not shown significant association with DDS. Full attention and symptomatic scales reflect attention, whereas full response control and attribute scales reflect behaviour. Therefore, DDS might be more related to attention rather than behaviour. Compared with full attention and symptomatic scales, response control and attribute scales might be more related to other factors such as biological factors compared with DDS. However, this subject needs further investigation.

In the present study, there was an inverse relationship between DDS and caffeine intake. Participants in the highest quartile of DDS had the lowest caffeine intake. Caffeine generally was found to improve attention, concentration, alertness and reduce fatigue in children and adults in other studies $^{(44-46)}$. The indirect effects of caffeine on concentration are attributed to its cognitive-promoting properties ${ }^{(45)}$. Caffeine intake of $3 \mathrm{mg} / \mathrm{kg}$ body weight has been shown to have a positive effect on sustained attention and consciousness ${ }^{(9)}$. However, caffeine consumption at usual intake (1.6 to $2.5 \mathrm{mg} / \mathrm{kg}$ ) in sugar-free cola has been shown to have no effect on sustained attention, learning and behaviour in children ${ }^{(46)}$. In most studies that showed positive results, caffeine was reported to be used as a high-dose supplement.

The findings of the present study may not be directly comparable to previous research because of differences in methods and the specific population of this study. However, in terms of food and food groups, it was concluded that variety in consumption of food groups might be related to better cognitive function.

There are some limitations to this study. First, subjects from all municipal and private sports clubs or from the whole population 
Table 3. Auditory and visual sustained attention across the quartiles of dietary diversity score (Adjusted mean values with their standard errors)

\begin{tabular}{|c|c|c|c|c|c|c|c|c|c|c|c|}
\hline \multirow[b]{3}{*}{ Scales and subscales of attention } & \multirow[b]{3}{*}{ Type } & \multirow[b]{3}{*}{ Model } & \multicolumn{8}{|c|}{ Dietary diversity score quartiles $†$} & \multirow[b]{3}{*}{$P^{*}$} \\
\hline & & & \multicolumn{2}{|c|}{ First $(n 78)$} & \multicolumn{2}{|c|}{ Second (n 79) } & \multicolumn{2}{|c|}{ Third (n 106) } & \multicolumn{2}{|c|}{ Fourth ( $n$ 117) } & \\
\hline & & & Mean & SE & Mean & SE & Mean & SE & Mean & SE & \\
\hline Full response control & Visual & $1 \neq$ & $111 \cdot 7$ & $2 \cdot 3$ & $107 \cdot 5$ & 3.6 & $113 \cdot 3$ & $2 \cdot 8$ & $113 \cdot 0$ & $2 \cdot 3$ & 0.3 \\
\hline & & $2 \S$ & $114 \cdot 0$ & $2 \cdot 8$ & $107 \cdot 0$ & 2.9 & 113.0 & $2 \cdot 8$ & 11.9 & $2 \cdot 4$ & 0.3 \\
\hline & & $3 \|$ & $114 \cdot 1$ & 3.0 & $107 \cdot 1$ & $2 \cdot 9$ & $113 \cdot 0$ & $2 \cdot 8$ & $111 \cdot 8$ & $2 \cdot 6$ & 0.3 \\
\hline & Auditory & $1 \neq$ & $99 \cdot 3$ & 1.9 & 99.2 & $2 \cdot 2$ & $101 \cdot 3$ & 1.7 & $101 \cdot 3$ & 0.9 & 0.1 \\
\hline & & $2 \S$ & 99.9 & 1.8 & 98.9 & 1.9 & $101 \cdot 2$ & 1.8 & $104 \cdot 4$ & 1.6 & 0.1 \\
\hline & & $3 \|$ & 99.9 & 2.0 & 98.9 & 1.9 & $101 \cdot 2$ & 1.8 & $104 \cdot 4$ & $1 \cdot 7$ & 0.2 \\
\hline Prudence & Visual & $1 \neq$ & $91 \cdot 1$ & 2.5 & 91.4 & 3.0 & 95.0 & $2 \cdot 8$ & 93.7 & $2 \cdot 4$ & 0.7 \\
\hline & & $2 \S$ & $93 \cdot 1$ & $2 \cdot 7$ & $91 \cdot 1$ & $2 \cdot 8$ & 94.5 & 2.7 & $92 \cdot 7$ & $2 \cdot 4$ & 0.8 \\
\hline & & $3 \|$ & $94 \cdot 3$ & 2.9 & $91 \cdot 1$ & 2.9 & 94.4 & 2.7 & 91.8 & 2.6 & 0.7 \\
\hline & Auditory & $1 \neq$ & $90 \cdot 8$ & $2 \cdot 1$ & 90.5 & $2 \cdot 8$ & $92 \cdot 1$ & $2 \cdot 2$ & 97.4 & 1.5 & 0.06 \\
\hline & & $2 \S$ & $92 \cdot 6$ & $2 \cdot 1$ & $90 \cdot 3$ & $2 \cdot 2$ & 91.6 & $2 \cdot 1$ & $96 \cdot 4$ & 1.9 & 0.1 \\
\hline & & $3 \|$ & 92.6 & $2 \cdot 3$ & $90 \cdot 2$ & $2 \cdot 3$ & 91.6 & $2 \cdot 2$ & 96.4 & $2 \cdot 0$ & 0.2 \\
\hline Consistency & Visual & $1 \neq$ & $119 \cdot 3$ & $2 \cdot 3$ & $119 \cdot 1$ & $3 \cdot 6$ & $120 \cdot 8$ & 2.7 & $122 \cdot 8$ & $2 \cdot 4$ & 0.7 \\
\hline & & $2 \S$ & $121 \cdot 1$ & 2.8 & $118 \cdot 8$ & 2.9 & $120 \cdot 5$ & 2.8 & 121.9 & 2.5 & 0.8 \\
\hline & & $3 \|$ & $120 \cdot 0$ & 3.0 & 118.7 & 3.0 & $120 \cdot 0$ & $2 \cdot 0$ & $122 \cdot 3$ & 2.7 & 0.8 \\
\hline & Auditory & $1 \neq$ & $106 \cdot 1$ & 1.6 & $107 \cdot 4$ & 1.9 & 107.5 & 1.5 & $110 \cdot 9$ & $1 \cdot 3$ & 0.1 \\
\hline & & $2 \S$ & $105 \cdot 6$ & 1.6 & $107 \cdot 1$ & 1.6 & $107 \cdot 7$ & 1.6 & 111.5 & 1.4 & 0.04 \\
\hline & & $3 \|$ & $104 \cdot 7$ & $1 \cdot 7$ & $106 \cdot 8$ & 1.7 & $107 \cdot 9$ & 1.6 & $112 \cdot 3$ & 1.5 & 0.01 \\
\hline Stamina & Visual & $1 \neq$ & $102 \cdot 4$ & $2 \cdot 1$ & 97.5 & 2.9 & $102 \cdot 8$ & 2.4 & $100 \cdot 5$ & $2 \cdot 0$ & 0.4 \\
\hline & & $2 \S$ & $103 \cdot 3$ & 2.4 & $97 \cdot 2$ & 2.5 & $102 \cdot 6$ & $2 \cdot 4$ & $100 \cdot 1$ & $2 \cdot 1$ & 0.3 \\
\hline & & $3 \|$ & 103.5 & $2 \cdot 6$ & $97 v 4$ & 2.5 & $102 \cdot 6$ & 2.4 & $102 \cdot 7$ & $2 \cdot 3$ & 0.3 \\
\hline & Auditory & $1 \neq$ & $102 \cdot 4$ & 1.7 & 98.9 & 1.8 & $102 \cdot 8$ & 2.4 & $100 \cdot 5$ & $2 \cdot 0$ & 0.3 \\
\hline & & $2 \S$ & $102 \cdot 2$ & 1.7 & 99.0 & 1.8 & $102 \cdot 6$ & 1.7 & $100 \cdot 3$ & 1.5 & 0.4 \\
\hline & & $3 \|$ & $103 \cdot 1$ & 1.8 & $99 \cdot 3$ & $1 \cdot 8$ & $102 \cdot 6$ & 1.7 & 99.5 & 1.6 & 0.3 \\
\hline Full attention & Visual & $1 \neq$ & $44 \cdot 2$ & $3 \cdot 1$ & 52.9 & 3.4 & $57 \cdot 4$ & 3.0 & 58.9 & $2 \cdot 8$ & 0.003 \\
\hline & & $2 \S$ & $45 \cdot 7$ & $3 \cdot 1$ & $52 \cdot 0$ & $3 \cdot 3$ & $57 \cdot 0$ & $3 \cdot 2$ & 58.7 & $2 \cdot 8$ & 0.01 \\
\hline & & $3 \|$ & $44 \cdot 8$ & 3.4 & $51 \cdot 8$ & 3.3 & $57 \cdot 2$ & $3 \cdot 2$ & $59 \cdot 4$ & 3.0 & 0.01 \\
\hline & Auditory & $1 \neq$ & 39.6 & $2 \cdot 7$ & $53 \cdot 2$ & $3 \cdot 1$ & $56 \cdot 9$ & 3.0 & $57 \cdot 1$ & 2.7 & $<0.001$ \\
\hline & & $2 \S$ & 40.9 & 2.9 & $52 \cdot 3$ & $3 \cdot 1$ & $56 \cdot 6$ & 3.0 & 56.9 & 9.0 & $<0.001$ \\
\hline & & $3 \|$ & 39.4 & $3 \cdot 2$ & $52 \cdot 0$ & $3 \cdot 1$ & 56.9 & 3.0 & $58 \cdot 1$ & $2 \cdot 8$ & $<0.001$ \\
\hline Vigilance & Visual & $1 \neq$ & $41 \cdot 1$ & $4 \cdot 7$ & $47 \cdot 0$ & $4 \cdot 1$ & 67.0 & 4.5 & $70 \cdot 4$ & 3.7 & 0.3 \\
\hline & & $2 \S$ & $47 \cdot 0$ & 1.8 & $50 \cdot 2$ & $2 \cdot 1$ & $45 \cdot 8$ & $4 \cdot 1$ & $54 \cdot 3$ & 3.5 & 0.3 \\
\hline & & $3 \|$ & $47 \cdot 1$ & 1.8 & $50 \cdot 2$ & $2 \cdot 2$ & 45.9 & $4 \cdot 2$ & 54.4 & 3.5 & 0.3 \\
\hline & Auditory & $1 \neq$ & $42 \cdot 6$ & 4.4 & 62.5 & 5.0 & $67 \cdot 2$ & $4 \cdot 6$ & 69.7 & 4.0 & 0.001 \\
\hline & & $2 \S$ & $44 \cdot 7$ & 4.6 & 61.9 & $4 \cdot 8$ & $66 \cdot 7$ & $4 \cdot 6$ & $68 \cdot 8$ & 4.0 & 0.001 \\
\hline & & $3 \|$ & $41 \cdot 3$ & $5 \cdot 0$ & $60 \cdot 7$ & $4 \cdot 8$ & 67.5 & $4 \cdot 6$ & 71.8 & $4 \cdot 3$ & $<0.001$ \\
\hline Focus & Visual & $1 \neq$ & $111 \cdot 2$ & $1 \cdot 2$ & 111.7 & $2 \cdot 1$ & $113 \cdot 1$ & $1 \cdot 2$ & $115 \cdot 3$ & 1.0 & 0.1 \\
\hline & & $2 \S$ & $113 \cdot 7$ & 3.0 & $116 \cdot 6$ & 3.2 & 118.4 & 3.0 & $119 \cdot 9$ & 2.7 & 0.04 \\
\hline & & $3 \|$ & 114.4 & $2 \cdot 1$ & $116 \cdot 6$ & 2.8 & 118.5 & 2.2 & $119 \cdot 3$ & $2 \cdot 8$ & 0.02 \\
\hline & Auditory & $1 \neq$ & $111 \cdot 2$ & 1.2 & 111.7 & $2 \cdot 1$ & $113 \cdot 1$ & $1 \cdot 2$ & $115 \cdot 3$ & 0.9 & 0.1 \\
\hline & & $2 \S$ & $110 \cdot 6$ & 1.4 & 111.9 & 1.4 & $113 \cdot 3$ & 1.4 & $115 \cdot 6$ & 1.2 & 0.03 \\
\hline & & $3 \|$ & $109 \cdot 6$ & 1.4 & $111 \cdot 3$ & 1.4 & 113.5 & 1.3 & $116 \cdot 6$ & $1 \cdot 3$ & 0.006 \\
\hline Speed & Visual & $1 \neq$ & 18.9 & $2 \cdot 8$ & $20 \cdot 6$ & $2 \cdot 6$ & $23 \cdot 8$ & $2 \cdot 2$ & 25.5 & $1 \cdot 8$ & 0.001 \\
\hline & & $2 \S$ & $20 \cdot 2$ & $2 \cdot 7$ & $20 \cdot 2$ & 2.7 & 23.4 & 2.7 & $30 \cdot 02$ & $2 \cdot 4$ & 0.01 \\
\hline & & $3 \|$ & $19 \cdot 8$ & 2.9 & $20 \cdot 2$ & $2 \cdot 8$ & 23.5 & 2.7 & 30.5 & 2.5 & 0.02 \\
\hline & Auditory & $1 \neq$ & $17 \cdot 0$ & 1.8 & 25.9 & 2.7 & $29 \cdot 0$ & $2 \cdot 3$ & 26.5 & 1.8 & 0.1 \\
\hline & & $2 \S$ & $18 \cdot 5$ & $2 \cdot 1$ & $25 \cdot 4$ & $2 \cdot 2$ & 28.6 & $2 \cdot 2$ & 25.9 & 1.9 & 0.01 \\
\hline & & $3 \|$ & $18 \cdot 4$ & $2 \cdot 3$ & $25 \cdot 6$ & $2 \cdot 3$ & $28 \cdot 6$ & $2 \cdot 2$ & 25.9 & $2 \cdot 0$ & 0.01 \\
\hline Attribute scale & & & & & & & & & & & \\
\hline Readiness & Visual & $1 \neq$ & $101 \cdot 6$ & $2 \cdot 1$ & $97 \cdot 4$ & 2.9 & $100 \cdot 3$ & 2.5 & 101.9 & $2 \cdot 0$ & 0.5 \\
\hline & & $2 \S$ & $102 \cdot 3$ & 2.4 & $97 \cdot 2$ & 2.5 & $100 \cdot 2$ & $2 \cdot 4$ & $101 \cdot 7$ & $2 \cdot 1$ & 0.4 \\
\hline & & $3 \|$ & $101 \cdot 0$ & $2 \cdot 6$ & $97 \cdot 3$ & 2.5 & $100 \cdot 3$ & $2 \cdot 4$ & $102 \cdot 5$ & $2 \cdot 3$ & 0.3 \\
\hline & Auditory & $1 \neq$ & $106 \cdot 7$ & $1 \cdot 7$ & $102 \cdot 9$ & $2 \cdot 6$ & $109 \cdot 0$ & 1.5 & $108 \cdot 7$ & 1.6 & $0 \cdot 2$ \\
\hline & & $2 \S$ & $107 \cdot 5$ & 1.9 & $102 \cdot 8$ & $2 \cdot 0$ & $108 \cdot 9$ & 1.9 & $108 \cdot 4$ & $1 \cdot 7$ & 0.1 \\
\hline & & $3 \|$ & $106 \cdot 7$ & $2 \cdot 1$ & $102 \cdot 9$ & $2 \cdot 0$ & $109 \cdot 0$ & 1.9 & $108 \cdot 9$ & 1.8 & 0.1 \\
\hline Balance & - & $1 \ddagger$ & $116 \cdot 2$ & $3 \cdot 1$ & $112 \cdot 1$ & $2 \cdot 1$ & $116 \cdot 4$ & $2 \cdot 1$ & $113 \cdot 1$ & 2.5 & 0.6 \\
\hline & & $2 \S$ & $116 \cdot 2$ & 2.9 & 111.9 & $3 \cdot 1$ & $116 \cdot 4$ & 3.0 & $112 \cdot 8$ & $2 \cdot 6$ & 0.6 \\
\hline & & $3 \|$ & $113 \cdot 8$ & $3 \cdot 2$ & $111 \cdot 3$ & $3 \cdot 1$ & $116 \cdot 9$ & $3 \cdot 0$ & $114 \cdot 7$ & $2 \cdot 8$ & 0.6 \\
\hline Symptomatic scale & & & & & & & & & & & \\
\hline Comprehension & Visual & $1 \ddagger$ & $50 \cdot 0$ & 4.5 & $66 \cdot 0$ & $4 \cdot 7$ & 71.4 & $4 \cdot 2$ & $75 \cdot 0$ & 3.6 & 0.5 \\
\hline & & $2 \S$ & $51 \cdot 3$ & $4 \cdot 3$ & 65.6 & 4.5 & $71 \cdot 1$ & 4.4 & 74.5 & 3.8 & 0.001 \\
\hline & & $3 \|$ & $45 \cdot 6$ & 4.6 & 63.7 & 4.5 & $72 \cdot 2$ & $4 \cdot 3$ & 79.6 & 4.0 & $<0.001$ \\
\hline & Auditory & $1 \neq$ & 45.5 & 4.4 & 61.6 & 5.0 & 71.0 & $4 \cdot 3$ & 74.5 & 3.8 & $<0.001$ \\
\hline & & $2 \S$ & $46 \cdot 2$ & 4.5 & 61.4 & $4 \cdot 7$ & $79 \cdot 8$ & 4.5 & $85 \cdot 2$ & 3.9 & $<0.001$ \\
\hline & & $3 \|$ & $40 \cdot 8$ & $4 \cdot 8$ & 59.6 & $4 \cdot 7$ & 71.9 & 4.5 & 89.0 & 4.2 & $<0.001$ \\
\hline
\end{tabular}


Table 3. Continued

\begin{tabular}{|c|c|c|c|c|c|c|c|c|c|c|c|}
\hline \multirow[b]{3}{*}{ Scales and subscales of attention } & \multirow[b]{3}{*}{ Type } & \multirow[b]{3}{*}{ Model } & \multicolumn{8}{|c|}{ Dietary diversity score quartiles $†$} & \multirow[b]{3}{*}{$P^{*}$} \\
\hline & & & \multicolumn{2}{|c|}{ First $(n 78)$} & \multicolumn{2}{|c|}{ Second $(n 79)$} & \multicolumn{2}{|c|}{ Third $(n 106)$} & \multicolumn{2}{|c|}{ Fourth $(n$ 117) } & \\
\hline & & & Mean & SE & Mean & SE & Mean & SE & Mean & SE & \\
\hline \multirow[t]{6}{*}{ Persistence } & Visual & $1 \neq$ & 92.5 & 3.2 & 79.8 & 4.6 & 98.4 & $2 \cdot 6$ & $97 \cdot 2$ & $2 \cdot 3$ & $<0.001$ \\
\hline & & $2 \S$ & 92.4 & $3 \cdot 2$ & $79 \cdot 8$ & 3.4 & 98.4 & 3.2 & $97 \cdot 3$ & $2 \cdot 9$ & $<0.001$ \\
\hline & & $3 \|$ & $93 \cdot 3$ & 3.5 & $80 \cdot 2$ & 3.4 & 96.5 & 3.0 & $98 \cdot 1$ & $3 \cdot 3$ & 0.001 \\
\hline & Auditory & 1f & $95 \cdot 0$ & $2 \cdot 6$ & $100 \cdot 1$ & $2 \cdot 2$ & $102 \cdot 9$ & $1 \cdot 7$ & $100 \cdot 9$ & 1.8 & 0.07 \\
\hline & & $2 \S$ & $95 \cdot 7$ & $2 \cdot 2$ & 99.9 & $2 \cdot 3$ & $102 \cdot 8$ & $2 \cdot 2$ & $100 \cdot 7$ & 1.9 & $0 \cdot 1$ \\
\hline & & $3 \|$ & $95 \cdot 7$ & $2 \cdot 4$ & 99.7 & $2 \cdot 3$ & $102 \cdot 9$ & $2 \cdot 2$ & $100 \cdot 8$ & $2 \cdot 1$ & 0.2 \\
\hline \multirow[t]{6}{*}{ Sensory/motor } & Visual & $1 \neq$ & $26 \cdot 6$ & $2 \cdot 4$ & 30.42 & $2 \cdot 9$ & $32 \cdot 3$ & $2 \cdot 6$ & 31.9 & $2 \cdot 3$ & 0.5 \\
\hline & & $2 \S$ & $37 \cdot 7$ & $2 \cdot 6$ & $40 \cdot 0$ & $2 \cdot 7$ & $42 \cdot 0$ & $2 \cdot 6$ & 41.4 & $2 \cdot 3$ & 0.6 \\
\hline & & $3 \|$ & $40 \cdot 0$ & $2 \cdot 8$ & $41 \cdot 2$ & $2 \cdot 7$ & $41 \cdot 4$ & $2 \cdot 6$ & $39 \cdot 2$ & $2 \cdot 4$ & 0.9 \\
\hline & Auditory & $1 \neq$ & $40 \cdot 9$ & $2 \cdot 3$ & 43.6 & $2 \cdot 1$ & $47 \cdot 6$ & 2.0 & 43.5 & 1.9 & 0.4 \\
\hline & & $2 \S$ & 52.6 & $2 \cdot 1$ & 53.1 & $2 \cdot 2$ & 57.2 & $2 \cdot 1$ & $52 \cdot 8$ & 1.9 & 0.3 \\
\hline & & $3 \|$ & $52 \cdot 0$ & $2 \cdot 3$ & 53.2 & $2 \cdot 2$ & $57 \cdot 2$ & $2 \cdot 0$ & $53 \cdot 1$ & $2 \cdot 2$ & 0.3 \\
\hline \multirow[t]{3}{*}{ Sustained auditory attention } & & $1 \neq$ & $23 \cdot 1$ & $3 \cdot 3$ & $40 \cdot 6$ & 4.2 & 49.4 & 3.9 & 54.5 & $3 \cdot 3$ & $<0.001$ \\
\hline & & $2 \S$ & $24 \cdot 4$ & $3 \cdot 8$ & $40 \cdot 2$ & 3.9 & $49 \cdot 1$ & $3 \cdot 8$ & $55 \cdot 9$ & $3 \cdot 3$ & $<0.001$ \\
\hline & & $3 \|$ & 21.2 & $4 \cdot 1$ & $39 \cdot 3$ & 4.0 & $49 \cdot 7$ & 3.8 & $57 \cdot 7$ & 3.5 & $<0.001$ \\
\hline \multirow[t]{3}{*}{ Sustained visual attention } & & $1 \neq$ & 25.45 & $3 \cdot 2$ & 39.4 & 3.9 & $45 \cdot 3$ & 3.5 & 48.9 & 3.2 & $<0.001$ \\
\hline & & $2 \S$ & 27.8 & 3.5 & 38.7 & 3.7 & $45 \cdot 7$ & 3.6 & 49.9 & $3 \cdot 1$ & $<0.001$ \\
\hline & & $3 \|$ & 24.1 & 3.8 & 37.6 & 3.7 & $45 \cdot 3$ & 3.5 & $51 \cdot 2$ & 3.3 & $<0.001$ \\
\hline
\end{tabular}

* $P$ value $<0.05$

† First quartile, numbers 2-3; second quartile, number 4; third quartile, number 5; fourth quartile, numbers 6-9.

$\ddagger P$ values for model 1 are from the ANOVA test and those for models 2 and 3 are from the ANCOVA test model 1 (crude model).

$\S$ Model 2 adjusted for age, years of education and physical activity.

|| Model 3 additionally adjusted for energy intake and BMI.

could not be included. It seems that the study subjects might be different in some aspects from the general population of women of the same age. For example, about $40 \%$ of the participants had college education. In contrast, this figure in 15-44-year-old urban women in Tehran was reported to be $19 \%{ }^{(47)}$. Therefore, the findings of this study might not be generalisable to other populations. Second, information on the participants' previous use of a computer, which might affect their performance, was not collected. However, in Tehran, most of the households have computers. In addition, participants were trained on how to use the mouse and keyboard before participating in the attention test. Third, 24-h dietary recall, which has several limitations, including having difficulty in remembering all foods, the exact serving size, underestimation and overestimation of portion sizes, was used ${ }^{(48)}$. In addition, using one $24 \mathrm{~h}$ recall period does not provide an indication of an individual's habitual diet.

Fourth, even though some conditions for performing the attention test were considered, some variables such as motivation, awareness and stress in participants might affect IVA CPT performance. Fifth, because the study was a cross-sectional one, the cause-effect relationship between the DDS and attention could not be established. DDS might affect the participant's attention, or subjects with higher attention might select more diverse foods. Sixth, although participants with Fe-deficiency anaemia were excluded from the study, the consequences of marginal deficiency of Fe, I, vitamin D and other nutrients remain unclear. However, the authors of this study are satisfied with the results, which clearly showed the association between DDS and sustained attention as one of the most widely used measures of cognitive performance.

In conclusion, the relationship between DDS and visual and auditory sustained attention was investigated. It was found that higher DDS is associated with better visual and auditory sustained attention. Further prospective cohort or interventional studies are needed to confirm whether a diversified diet might improve nutritional status and promote cognitive function.

\section{Acknowledgements}

The authors would like to express their gratitude to the subjects for their willingness to participate.

This research has been supported by Tehran University of Medical Sciences (grant number 92-01-161-22306). Tehran University of Medical Sciences had no role in the design, analysis or writing of this article.

F. Shiraseb, O. M. S and E. N. recruited the patients and collected the data, performed laboratory tests and drafted the manuscript. G. S. and F. Siassi supervised the research project, contributed to the study design and reviewed the manuscript. M. Q. analysed the data and contributed to the interpretation of results and writing of the manuscript. R. R. performed the sustained attention test and reviewed the manuscript. P. Y. contributed to the interpretation of results and reviewed the manuscript.

There are no conflicts of interest.

\section{References}

1. Stroop JR (1935) Studies of interference in serial verbal reactions. J Exp Psychol 18, 643-661.

2. Spreen $\mathrm{O} \&$ Strauss E (1998) A Compendium of Neuropsychological Tests: Administration, Norms, and Commentary, 2nd ed. New York: Oxford University Press. 
3. Joseph JS, Chun MM \& Nakayama K (1997) Attentional requirements in 'preattentive' feature search task. Nature $\mathbf{3 8 7}$ 805-807.

4. Neumann E \& DeSchepper BG (1991) Costs and benefits of targets activation and distractor inhibition in selective attention. J Exp Psychol Learn 17, 1136-1145.

5. Bourre JM (2006) Effects of nutrients (in food) on the structure and function of the nervous system: update on dietary requirements for brain. Part 2: macronutrients. J Nutr Health Aging 10, 386-399.

6. Bourre JM (2006) Effects of nutrients (in food) on the structure and function of the nervous system: update on dietary requirements for brain. Part 1: micronutrients. J Nutr Health Aging 10, 377-385.

7. Martorell R (1996) The role of nutrition in economic development. Nutr Rev 54, 66-71.

8. Smith A (2002) Effects of caffeine on human behavior. Food Chem Toxicol 40, 1243-1255.

9. Brice C \& Smith A (2001) The effects of caffeine on simulated driving, subjective alertness and sustained attention. Hum Psychopharmacol 16, 523-531.

10. Gillette-Guyonnet S, Abellan VK, Andrieu S, et al. (2007) IANA task force on nutrition and cognitive decline with aging. J Nutr Health Aging 11, 132-152.

11. Polidori MC, Praticó D, Mangialasche F, et al. (2009) High fruit and vegetable intake is positively correlated with antioxidant status and cognitive performance in healthy subjects. J Alzheimers Dis 17, 921-927.

12. Kang JH, Ascherio A \& Grodstein F (2005) Fruit and vegetable consumption and cognitive decline in aging women. Ann Neurol 7, 713-720.

13. Morris MC, Evans DA, Tangney CC, et al. (2006) Associations of vegetable and fruit consumption with age-related cognitive change. Neurology 67, 1370-1376.

14. Padayatty SJ \& Levine M (2008) Fruit and vegetables: think variety, go ahead, eat!. Am J Clin Nutr 87, 5-7.

15. Cox DR, Skinner JD, Carruth BR, et al. (1997) A food variety index for toddlers (VIT): development and application. J Am Diet Assoc 97, 1382-1386.

16. Katz DL (2008) Nutrition in Clinical Practice: A Comprebensive, Evidence-Based Manual for the Practitioner. pp. 362-368. Philadelphia, PA: Lippincott Williams \& Wilkins.

17. Haloly A, Torhcim LE \& Oshaung A (1998) Food variety a good indicator of nutritional adequacy of the diet? A case study from an urban area in Mali West Africa. Eur J Clin Nutr 52, 891-898.

18. Ruel MT \& Alderman H (2013) Nutrition-sensitive interventions and programmes: how can they help to accelerate progress in improving maternal and child nutrition? Lancet 382, 536-551.

19. Kant AK, Schatzkin A, Ziegler RG, et al. (1991) Dietary diversity in the US population NHANES II 1970-80. J Am Diet Assoc 15, 26-31.

20. Torheim LE, Ouattar F, Diarra MM, et al. (2004) Nutrient adequacy and dietary diversity in rural Mali: association and determinants. Eur J Clin Nutr 58, 594-604.

21. Grebmer KV, Saltzman A, Birol E, et al. (2014) Global Hunger Index: The Challenge of Hidden Hunger, International Food Policy Research Institute, and Concern Worldwide. Bonn, Washington, DC and Dublin: Welthungerhilfe.

22. Miller NL, Crabtree BF \& Evans DK (1992) Exploratory study of the relationship between hypertension and public diet diversity among Saba Istandders. Public Health Rep 107, 426-432.

23. Hodgson JM, Hsu-Hage B \& Wahlqvist ML (1994) Dietary diversity and health. Am J Clin Nutr 59, 950-951.
24. Kennedy G, Ballard T \& Dop MC (2013) Guidelines for Measuring Housebold and Individual Dietary Diversity. Rome: FAO of the UN.

25. Florence MD, Asbridge M \& Veugeleqp JP (2008) Diet quality and academic performance. $J$ Sch Health $\mathbf{7 8}$, 209-215.

26. Narmaki E, Siassi F, Koohdani F, et al. (2015) Dietary diversity as a proxy measure of blood antioxidant status in women. Nutrition 31, 722-726.

27. Shiraseb F, Siassi F, Sotoudeh G, et al. (2015) Association of blood antioxidants status with visual and auditory sustained attention. Nutr Neurosci 18, 337-346.

28. Berzosa C, Cebrián I, Fuentes-Broto L, et al. (2011) Acute exercise increases plasma total antioxidant status and antioxidant enzyme activities in untrained men. $J$ Biomed Biotechnol 2011, 540458.

29. Ratey JJ \& Loehr JE (2011) The positive impact of physical activity on cognition during adulthood: a review of underlying mechanisms, evidence and recommendations. Rev Neurosci 22, 171-185.

30. Anne S \& Paula B (2006) Household dietary diversity score (HDDS) for measurement of household food access: indicator guide (v.2), Food and Nutrition Technical Assistance Project (FANTA), Academy for Educational Development, Washington, DC.

31. Ghaffarpour M, Houshiar-Rad A \& Kianfar H (1999) The Manual for Household Measures, Cooking Yields Factors and Edible Portion of Foods. Tehran: Nashre Olume Keshavarzy Press (In Persian).

32. Aadahl M \& Jorgensen $T$ (2003) Validation of a new self-report instrument for measuring physical activity. Med Sci Sport Exerc 35, 1196-1202.

33. Kelishadi R, Rabieik K, Khosravi A, et al. (2004) Assessment of physical activity in adolescents of Isfahan. J Shabrekord Univ Med Sci 3, 55-66 (In Persian).

34. Sandford JA \& Turner A (2011) IVA+Plus Visual and Auditory Attention Testing. Richmond, VA: Brain Train.

35. Péneau S, Galan P, Jeandel C, et al. (2011) Fruit and vegetable intake and cognitive function in the SU. VI. MAX 2 prospective study. Am J Clin Nutr 94, 1295-1303.

36. Loef M \& Walach H (2012) Fruit, vegetables and prevention of cognitive decline or dementia: a systematic review of cohort studies. J Nurt Health Aging 16, 626-630.

37. Solfrizzi V, Panza F \& Capurso A (2003) The role of diet in cognitive decline. J Neural Transm 110, 95-110.

38. Singh RP, Sharad S \& Kapur S (2004) Free radicals and oxidative stress in neurodegenerative diseases: relevance of dietary antioxidants. I Indian Acad Clin Med 5, 218-225.

39. Wärnberg J, Gomez-Martinez S, Romeo J, et al. (2009) Nutrition, inflammation, and cognitive function. Ann N Y Acad Sci 1153, 164-175.

40. Ruel MT (2003) Operationalizing dietary diversity: a review of measurement issues and research priorities. J Nutr 133, 3911-3926.

41. Drimie S, Faber M, Vearey J, et al. (2013) Dietary diversity of formal and informal residents in Johannesburg, South Africa. BMC Public Health 13, 911.

42. Rathnayake KM, Madushani PAE \& Silva KDRR (2012) Use of dietary diversity score as a proxy indicator of nutrient adequacy of rural elderly people in Sri Lanka. BMC Res Notes 5, 469 .

43. Mirmiran P, Azadbakht L, Esmaillzadeh A, et al. (2004) Dietary diversity score in adolescents-a good indicator of the nutritional adequacy of diets: Tehran lipid and glucose study. Asia Pac J Clin Nutr 13, 56-60. 
44. Serra-Grabulosa JM, Adan A, Falcón C, et al. (2010) Glucose and caffeine effects on sustained attention: an exploratory fMRI study. Hum Psychopharmacol 25, 543-552.

45. Nehlig A (2010) Is caffeine a cognitive enhancer? J Alzheimers Dis 20, 85-94.

46. Baer RA (1987) Effect of caffeine on classroom behavior, sustained attention, and a memory task in preschool children. J Appl Behav Anal 20, 225-234.
47. Farbakhsh F, Shafizada T, Ramazankhani A, et al. (2007) The relationship between BMI and socio-demographic factors in 44-15 year old women in Tehran. Res Med J 31, 133-139 (In Persian).

48. Ferguson EL, Gibson RS, Ounpuu S, et al. (1989) The validity of the 24-hour recall for estimating the energy and selected nutrient intake of a group of rural Malawian preschool children. Ecol Food Nutr 23, 273-285. 